\title{
REVIEW
}

\section{Next generation multifunctional angiotensin receptor blockers}

\author{
Theodore W Kurtz ${ }^{1}$ and Uwe Klein ${ }^{2}$
}

Angiotensin receptor blockers (ARBs) are well-tolerated drugs that are known to be useful for inhibiting activity of the reninangiotensin (RAS) system, treating hypertension and reducing the risk for cardiovascular disease. However, inhibition of the RAS does not control all pathophysiological mechanisms of hypertension or cardiovascular risk and many patients continue to suffer from cardiovascular events and metabolic disturbances despite being treated with an ARB, an angiotensin-converting enzyme inhibitor or both, in addition to other standard therapies for cardiovascular disease. Recently, it has become apparent that bifunctional molecules can be designed that do more than just block $\mathrm{AT}_{1}$ receptors and that can target additional mechanisms of hypertension, cardiovascular disease and diabetes besides just increased activity of the renin-angiotensin system. Specifically, next generation ARBs are becoming available that are intended to not only antagonize $\mathrm{AT}_{1}$ receptors, but also block endothelin receptors, function as nitric oxide donors, inhibit neprilysin activity and increase natriuretic peptide levels, or stimulate the peroxisome proliferator-activated receptor $\gamma$ (PPAR $\gamma$ ). In this review, we: (1) discuss the potential importance of multifunctional ARBs that can reduce cardiovascular and metabolic risk through multiple mechanisms that go beyond just inhibition of the renin-angiotensin system and (2) describe specific examples of next generation ARBs in development that are intended to do more than simply block $\mathrm{AT}_{1}$ receptors.

Hypertension Research (2009) 32, 826-834; doi:10.1038/hr.2009.135; published online 28 August 2009

Keywords: angiotensin; angiotensin receptor blockers; azilsartan; telmisartan; PPAR

\section{INTRODUCTION}

The discovery and clinical use of first generation nonpeptide angiotensin II receptor antagonists represents a major success story in the history of cardiovascular medicine. ${ }^{1,2}$ These molecules were designed to block angiotensin II type $1\left(\mathrm{AT}_{1}\right)$ receptors with the goal of reducing blood pressure and the risk for cardiovascular events. Angiotensin II receptor blockers (ARBs) in use today are very well-tolerated antihypertensive drugs and are considered to offer protection against stroke, renal damage and cardiovascular disease. ${ }^{2}$ Angiotensin-converting enzyme inhibitors (ACEis) can provide all the same clinical benefits if not more than those provided by ARBs. ${ }^{3,4}$ However, ARBs are generally better tolerated as they are associated with a significantly lower risk of cough and angioedema than ACE inhibitors. ${ }^{4-7}$ Renin inhibitors represent a more recently developed class of molecules also designed to inhibit activity of the renin-angiotensin system (RAS) and lower blood pressure. However, there is a paucity of cardiovascular outcome data for this group of drugs. Results from large-scale comparative clinical trials will be required to determine whether renin inhibitors provide any greater benefits than other available drugs that inhibit the RAS through different mechanisms.

\section{THE MOTIVATION FOR NEXT GENERATION ANGIOTENSIN RECEPTOR BLOCKERS}

Given the well-established ability of currently available ARBs to safely block $\mathrm{AT}_{1}$ receptors and reduce blood pressure, little motivation might seem to exist for developing next generation ARBs for use in clinical practice. However, on the basis of the results of controlled clinical trials together with recent advances in our understanding of the pathophysiology of cardiovascular disease and diabetes, it has become increasingly clear that currently available ARBs leave much to be desired when it comes to reducing cardiovascular and metabolic risk in patients with hypertension. In this review, we discuss some of the major unmet needs of hypertensive patients being treated with existing ARBs and highlight new efforts underway to develop next generation ARBs that are expected to provide superior control of blood pressure and associated cardiovascular and metabolic risk factors in patients with hypertension. The ability of medicinal chemists to design bifunctional molecules that not only block $\mathrm{AT}_{1}$ receptors but also target other pathways involved in the regulation of blood pressure and the pathogenesis of cardiovascular and metabolic diseases has opened the door for the development of next generation ARBs that do more than just inhibit the renin-angiotensin system (Table 1).

${ }^{1}$ Department of Laboratory Medicine, University of California, San Francisco, San Francisco, CA, USA and ${ }^{2}$ Molecular and Cellular Biology, Theravance Inc., South San Francisco, CA, USA

Correspondence: Professor TW Kurtz, Department of Laboratory Medicine, University of California, San Francisco, 185 Berry Street, Suite 290, San Francisco, CA 94107, USA. E-mail: kurtzt@labmed2.ucsf.edu

Received 8 July 2009; revised 3 August 2009; accepted 4 August 2009; published online 28 August 2009 
Table 1 Next generation ARBs with actions beyond $\mathrm{AT}_{1}$ receptor blockade

\begin{tabular}{|c|c|c|c|}
\hline Molecule & Stage & Special action & References \\
\hline Azilsartan & Phase III & Increase PPAR $\gamma$ gene expression ${ }^{\mathrm{a}}$ & $35-39$ \\
\hline K-868 & Preclinical & PPAR $\gamma$ partial agonism ${ }^{b}$ & 43 \\
\hline PF-03838135 & Preclinical & PPAR $\gamma$ partial agonism ${ }^{b}$ & 44 \\
\hline ARNI & Preclinical & Neprilysin inhibition ${ }^{\mathrm{b}}$ & $55-58$ \\
\hline LCZ-696 & Phase $\|/\| I \mid$ & Neprilysin inhibition ${ }^{c}$ & $59-62$ \\
\hline PS433540 & Phase IIb & Endothelin receptor antagonism ${ }^{b}$ & 74,76 \\
\hline WB1106 & Preclinical & Nitric oxide donor ${ }^{\mathrm{b}}$ & 86 \\
\hline $3-[($ nitrooxy)methyl] benzoate ester of losartan & Preclinical & Nitric oxide donor ${ }^{\mathrm{b}}$ & 84,85 \\
\hline
\end{tabular}

aFeature observed by chance-not deliberately sought in the $\mathrm{AT}_{1}$ receptor antagonist.

bFeature deliberately sought and achieved together with $\mathrm{AT}_{1}$ receptor-blocking activity in a single molecule.

'Feature deliberately sought and achieved by linking a neprilysin inhibitor to an $\mathrm{AT}_{1}$ receptor antagonist (two molecules).

\section{ANGIOTENSIN RECEPTOR BLOCKERS: CURRENT LIMITATIONS AND UNMET NEEDS}

All clinically approved angiotensin receptor antagonists can block $\mathrm{AT}_{1}$ receptors and reduce blood pressure. As increased activity of the renin-angiotensin system is believed to contribute to end organ damage, considerable emphasis has been placed on the still controversial notion that ARBs can afford major benefits on cardiovascular outcome beyond their ability to reduce blood pressure. Although the clinically used ARBs can differ with respect to pharmacokinetic characteristics such as half life, potency for $\mathrm{AT}_{1}$ receptor blockade, degree of insurmountable antagonism, etc, one can usually minimize the practical impact of these differences on control of RAS activity and antihypertensive efficacy by making dose adjustments. ${ }^{8}$ Thus, if one simply administers the appropriate doses required to control blood pressure and effectively inhibit the renin-angiotensin system, it is generally assumed that all ARBs will yield equally satisfactory protection against risk for cardiovascular disease.

Unfortunately, administration of ARBs in doses considered sufficient to robustly block $\mathrm{AT}_{1}$ receptors often fails to provide effective blood pressure control and to protect against adverse cardiovascular events. ${ }^{79}$ Furthermore, a recent report by a panel of experts assembled by the American Heart Association points to the increasing problem of difficult-to-treat and outright drug-resistant hypertension, ${ }^{10}$ which is most pronounced in certain subpopulations including African Americans, patients with isolated systolic hypertension, and those with concomitant cardiovascular and renal disease, metabolic syndrome or diabetes. Even if one administers a powerful ARB in combination with an ACEi to fully inhibit the renin-angiotensin system, many high-risk patients, including those getting their blood pressure controlled and those taking statins and aspirin, still suffer from adverse cardiovascular events. ${ }^{7}$ In addition, notwithstanding evidence that the risk for new onset diabetes is lower in patients taking ARBs or ACEis than in patients taking other antihypertensive drugs known to cause disturbances in glucose metabolism, ${ }^{11}$ many patients still develop diabetes despite taking ARBs, ACEis or both. Moreover, most ARBs have never been compared against placebo in randomized, double-blind trials and it is unknown whether ARBs as a class are capable of reducing the risk for new onset diabetes. As hypertension itself is associated with increased risk for diabetes and is often accompanied by multiple metabolic disturbances that strongly promote diabetes, ${ }^{12-14}$ it is important to reduce the risk for diabetes linked to hypertension rather than to simply avoid the risk for diabetes caused by certain kinds of antihypertensive drugs. Furthermore, regardless of the ongoing controversy over whether the diabetes that develops during hypertension treatment is associated with increased cardiovascular risk, diabetes per se is a highly undesirable problem that negatively affects the quality of life in many ways and significantly increases health-care costs. Thus, the availability of multifunctional ARBs that are more effective than existing ARBs in lowering blood pressure and enabling patients to reach blood pressure goals, protecting against new onset diabetes, and reducing overall cardiovascular risk would be of considerable clinical and financial value.

\section{MULTIFUNCTIONAL THERAPEUTICS: GOING BEYOND $\mathrm{AT}_{1}$ RECEPTOR BLOCKADE}

It could be argued that greater therapeutic benefits might be gained by administration of higher doses of existing ARBs, and several studies have been conducted to test this notion (for example, Shargorodsky et al. ${ }^{15}$ and Hollenberg et al. $\left.{ }^{16}\right)$. However, such a strategy fails to address the need to control the other pathogenetic determinants of hypertension, diabetes and cardiovascular disease that do not depend solely on increased activity of the renin-angiotensin system. It is widely recognized that effective control of these multifactorial disorders requires the therapeutic modulation of multiple pathways involved in disease pathogenesis. For example, when given as monotherapy for hypertension, ARBs often fail to sufficiently lower blood pressure. ${ }^{9}$ Thus, many patients require two or more drugs from different classes with different pharmacologies to control hypertension and combination therapy is becoming more and more the mainstay of treatment. ${ }^{17}$

\section{COMBINATION THERAPIES VS. MULTIFUNCTIONAL MOLECULES: PROS AND CONS}

There are principally three different approaches to targeting multiple pharmacologies when treating multifactorial disorders such as hypertension. ${ }^{18}$ Most commonly, patients are given a cocktail of two or more different drugs. Although this option allows for maximal flexibility with respect to possible drug combinations and different dosages, it suffers from (a) potentially poor adherence to treatment by the patient because of the increased pill burden and differing dosing schedules for the individual drugs, (b) possible incompatibilities because of drug-drug interactions, and (c) increased risk of drug side effects. These problems can reduce the effectiveness of therapy and hamper the attainment of treatment goals particularly in the management of chronic, asymptomatic disorders such as hypertension.

The second approach relies on the use of fixed-dose combinations of drugs in a single dosage form. In patients with hypertension, fixeddose combinations have become increasingly popular in recent years because they reduce pill burden, result in improved patient compliance and often improve blood pressure-lowering and patient responder rates. ${ }^{19}$ Fixed-dose combinations of angiotensin-converting 
enzyme inhibitors or angiotensin receptor blockers with diuretics have increased significantly in market share, and the recent FDA approval of Exforge HCT (a combination of the ARB valsartan, the calcium channel blocker amlodipine and the diuretic hydrochlorothiazide marketed by Novartis, East Hanover, NJ, USA) now provides the first treatment option for hypertension with triple pharmacology in a single tablet. The disadvantage of fixed-dose combinations is primarily the limited choice of possible dose ratios between the active ingredients, which makes it more difficult to properly titrate the individual patient to maximum efficacy with minimal adverse effects. In case of treatment-emergent adverse effects, it may be difficult to determine which of the individual components is responsible. In addition, different pharmacokinetic properties of the components in the combination might lead to a complex temporal mismatch in pharmacodynamic effects at the individual targets thereby compromising overall efficacy.

The third approach to the treatment of multifactorial disorders is the use of multifunctional drugs that combine two or more pharmacologies in a single compound. Although the discovery of such multifunctional compounds is more complex and requires substantial investigation into the optimal ratio of target activities in the molecule, both their development and clinical use are simplified because of the unified pharmacokinetics, resulting in matched pharmacodynamic activities at the molecular targets. Although therapeutic approaches that involve the administration of multiple drugs in combination are certainly of value, advances in medicinal chemistry, rational drug design and high throughput screening have made it possible to discover multifunctional molecules that modulate more than one molecular target, show two or more pharmacologies and meet several therapeutic objectives with a single agent. It should be noted that multifunctional molecules may also be amenable to fixed dose combination with other drugs thereby combining three or even four pharmacologies in a single pill to produce further increments in efficacy.

\section{A PROTOTYPE FOR NEXT GENERATION ARBS}

Recent studies by Benson et al. ${ }^{20}$ and Schupp et al. ${ }^{21}$ provided a clue that it might be possible to develop multifunctional ARBs that not only block angiotensin II receptors but also stimulate the activity of a separate molecular target useful for the prevention of diabetes. These investigators observed that the angiotensin II receptor antagonist telmisartan not only blocked $\mathrm{AT}_{1}$ receptors but could also partially activate the peroxisome proliferator-activated receptor- $\gamma$ (PPAR $\gamma)$, an established target of thiazolidinedione drugs with known efficacy for the prevention and treatment of type II diabetes. ${ }^{20,21}$ This raised the possibility that in addition to being useful for treating hypertension, telmisartan might be capable of reducing the risk for new onset diabetes. In addition, as telmisartan activates PPAR $\gamma$ less robustly and differently than do thiazolidinediones, the use of telmisartan is not associated with the kinds of side effects that have plagued the use of full PPAR $\gamma$ agonists, such as rosiglitazone or pioglitazone. ${ }^{22}$

The latest results from large-scale, randomized, double-blind clinical trials are consistent with the possibility that telmisartan might have true antidiabetic properties (that is, be capable of decreasing the risk for developing new onset diabetes when compared with placebo, not just when compared with other antihypertensive drugs that are associated with increased risk for diabetes). Figure 1 shows the results of a meta-analysis of two randomized, double-blind, placebo-controlled trials with telmisartan in which the incidence of new onset diabetes was measured as a pre-specified secondary end point. This meta-analysis of the TRANSCEND ${ }^{23}$ and PRoFESS trials ${ }^{24}$ indicates that telmisartan can reduce the risk for new onset diabetes by

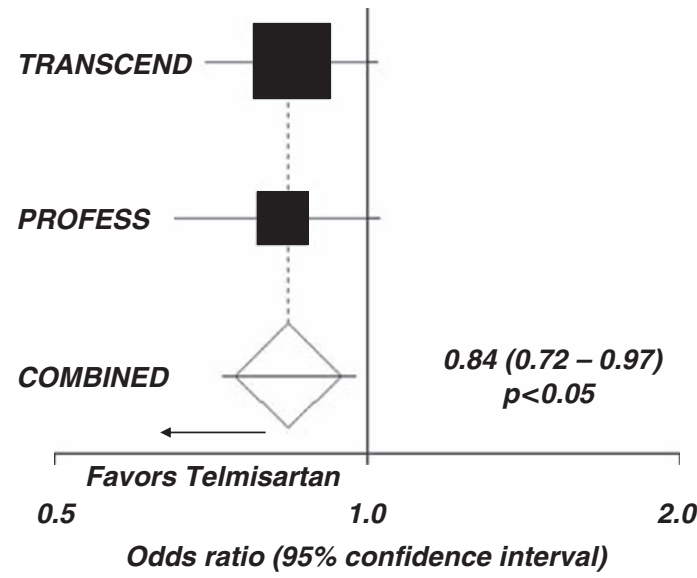

Figure 1 Meta-analysis of the antidiabetic effects of telmisartan. Metaanalysis showing the effects of telmisartan treatment on risk for new onset diabetes compared with placebo treatment in the TRANSCEND and PRoFESS trials. The results show a significant antidiabetic effect of telmisartan with a point estimate reduction in risk for new onset diabetes of $16 \%$.

Hypertension -Diabetes Cascade

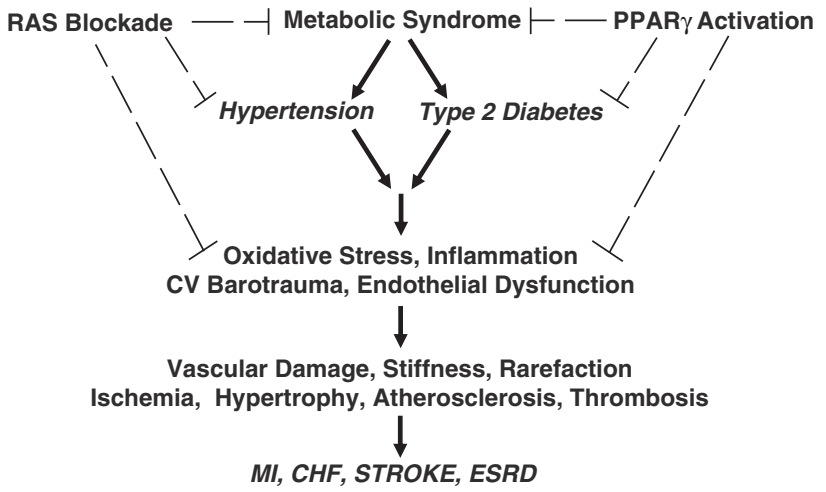

Figure 2 The hypertension-diabetes cascade. Diagram showing that inhibitors of the renin-angiotensin system (RAS) and activators of PPAR interrupt at multiple points early in the hypertension-diabetes cascade.

approximately $16 \%$ compared with placebo in high cardiovascular risk patients without heart failure. This antidiabetic effect of telmisartan is similar in overall magnitude to that observed with ACE inhibitors in placebo-controlled clinical trials of patients without heart failure. ${ }^{25,26}$ Few randomized, double-blind, placebo-controlled trials have been performed that have examined the antidiabetic effects of other ARBs in patients without heart failure. ${ }^{27}$

Just as ACE inhibitors are believed to improve glucose metabolism through at least two or more primary mechanisms (for example, inhibition of the renin-angiotensin system and activation of the bradykinin/nitric oxide pathways), ${ }^{28-31}$ it is possible that telmisartan might also be improving glucose metabolism and cardiovascular protection through two or more key pathways (for example, inhibition of the renin-angiotensin system and activation of PPAR $\gamma$ ). By the use of multifunctional ARBs that have the potential to target multiple points in the hypertension-diabetes cascade (Figure 2), it is conceivable that one might achieve greater metabolic and cardiovascular protection than that attained with the angiotensin receptor blockade 


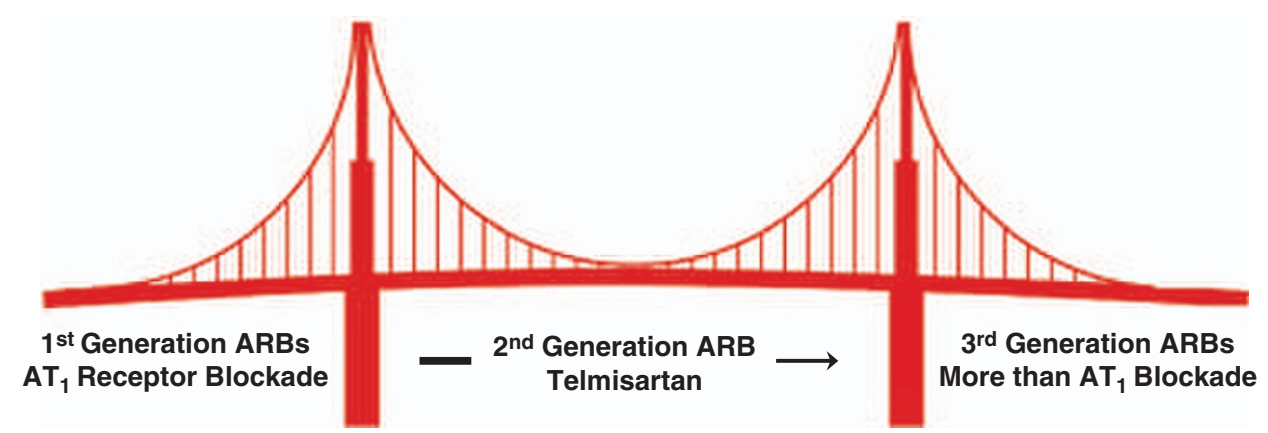

Figure 3 Bridge to the future of next generation ARBs. Illustration depicting telmisartan as a bridge to the future between first generation ARBs focused almost entirely on the $A T_{1}$ receptor blockade and next generation ARBs intended to do more than just block $\mathrm{AT}_{1}$ receptors.

alone. In addition, the antidiabetic properties of multifunctional ARBs such as telmisartan may be useful in counteracting the pro-diabetic effects of diuretic agents that are often used in combination with $\mathrm{AT}_{1}$ receptor antagonists. It should be noted, however, that telmisartan was not specifically developed for the purpose of activating PPAR $\gamma$ and that it is not a highly potent PPAR $\gamma$ agonist. The doses of telmisartan used in the TRANSCEND and PRoFESS trials were not optimized with the intent of achieving PPAR $\gamma$ activation. Thus, the administration of higher doses of telmisartan or the use of next generation ARBs with more potent effects on PPAR $\gamma$ activity will likely be required to achieve greater antidiabetic effects than those revealed by the metaanalysis of the TRANSCEND and PRoFESS trials. In light of these observations, telmisartan might be viewed as a bridge to the future between first generation ARBs focused almost entirely on $\mathrm{AT}_{1}$ receptor blockade and next generation ARBs that are intended to do more than just inhibit activity of the RAS (Figure 3). Although the work on telmisartan has suggested the feasibility of creating new ARBs with effects on receptor pathways beyond the renin-angiotensin system, structure-activity relationship studies of telmisartan may also prove useful in guiding the future development of next generation PPAR $\gamma$ ligands as well. ${ }^{32}$

As noted, inhibition of the renin-angiotensin system itself is believed to have a positive effect on glucose metabolism; however, the magnitude of any such effect is likely to depend on the nature of the underlying disturbance in glucose homeostasis. In some circumstances, inhibition of the RAS is thought to improve glucose handling at least in part by enhancing tissue blood flow and the delivery of glucose to skeletal muscle beds where it undergoes extraction and metabolism. ${ }^{31,33}$ Thus, in situations such as congestive heart failure where peripheral glucose metabolism may be significantly impaired owing to reduced tissue perfusion, any drug that inhibits the RAS and improves the microcirculatory function might be anticipated to improve glucose metabolism. This could partly explain why the ARB candesartan was observed to have antidiabetic effects in heart failure patients studied in the CHARM trial but did not reduce the risk for new onset diabetes in a randomized, double-blind, placebocontrolled study conducted in patients without heart failure. ${ }^{27,34}$ In contrast, ARBs that have the ability to improve glucose metabolism through mechanisms such as partial PPAR $\gamma$ agonism and not just RAS blockade may hold greater promise for protecting against new onset diabetes in patients without heart failure. The meta-analysis results showing the antidiabetic effects of telmisartan in high CV risk patients without heart failure suggest that it might be feasible to develop next generation ARBs with greater PPAR $\gamma$ potency and greater efficacy than existing ARBs for reducing the risk of new onset diabetes in patients with hypertension.

\section{NEXT GENERATION ARBS THAT AFFECT PPAR $\gamma$}

Several major pharmaceutical companies have identified new ARBs that can increase PPAR $\gamma$ gene expression or receptor activity in a manner that holds promise for enhancing the antidiabetic potential of these agents (Table 1). Takeda Pharmaceuticals (Deerfield, IL, USA) has been conducting Phase II and Phase III clinical trials of the next generation ARB azilsartan (TAK-536) and its prodrug azilsartan medoxomil (TAK-491) in patients with hypertension. ${ }^{35-37}$ Azilsartan is a potent $\mathrm{AT}_{1}$ receptor antagonist that is structurally similar to candesartan except for bearing a 5-oxo-1,2,4-oxadiazole moiety in place of a tetrazole ring (Figure 4). ${ }^{38}$ Azilsartan is less acidic and more lipophilic than candesartan and in preclinical studies has been shown to be significantly more potent than candesartan in improving glucose tolerance and tissue glucose metabolism. ${ }^{39}$ In cell-based receptor transactivation studies in vitro, azilsartan appears to have little or no direct effect on PPAR $\gamma$ activity. ${ }^{39}$ However, in a mouse model of type II diabetes, oral administration of very low doses of azilsartan has been found to significantly increase PPAR $\gamma$ gene expression in adipose tissue. $^{39}$ Dose response studies in vivo showed that azilsartan is much more potent in stimulating PPAR $\gamma$ gene expression than candesartan. ${ }^{39}$ These observations raise the possibility that azilsartan may have stronger antidiabetic effects than candesartan and perhaps other ARBs as well. Takeda is also conducting Phase III clinical trials of azilsartan medoxomil in combination with chlorthalidone, a benzenesulfonamide diuretic that has been shown to have signifi cant cardioprotective effects in large-scale clinical trials. ${ }^{40,41}$ Depending on the extent to which azilsartan shows enhanced antidiabetic properties, its metabolic benefits might offset or even override the adverse effects of chlorthalidone on glucose metabolism. ${ }^{42}$ If so, the combination of azilsartan and chlorthalidone could become particularly attractive from both a metabolic and hemodynamic perspective.

Recently, Kyowa Hakko Kirin pharmaceuticals (Tokyo, Japan) has reported the development of a next generation ARB-designated K-868 with high binding affinity for $\mathrm{AT}_{1}$ receptors and that also functions as a partial agonist of PPAR $\gamma$ with improved metabolic properties relative to other ARBs. ${ }^{43}$ In a variety of preclinical models of hypertension, K-868 has been shown to have antihypertensive properties similar to candesartan. At the same time, K-868 appears to have more robust metabolic effects than do candesartan and other ARBs. In the prediabetic Zucker fatty rat model of obesity and insulin resistance, oral administration of K-868 improved glucose tolerance, reduced insulin levels and inhibited increases in glucose and hemoglobin A1c levels, whereas oral administration of similar doses of candesartan did not. In the Zucker diabetic fatty rat, the administration of a relatively low dose of $\mathrm{K}-868\left(1 \mathrm{mg} \mathrm{kg}^{-1}\right)$ reduced proteinuria 
<smiles>CCOc1nc2cccc(C(=O)O)c2n1Cc1ccc(-c2ccccc2-c2nc(=O)o[nH]2)cc1</smiles>

Azilsartan<smiles>CCCCC1=NC2(CCCC2)C(=O)N1Cc1ccc(-c2ccccc2S(=O)(=O)Nc2noc(C)c2C)c(COCC)c1</smiles>

PS-433540<smiles>CCCCc1nc(Cl)c(COC(=O)c2cccc(CO[N+](=O)[O-])c2)n1Cc1ccc(-c2ccccc2-c2nnn[nH]2)cc1</smiles>

3-[(Nitrooxy)methyl]benzoate Losartan

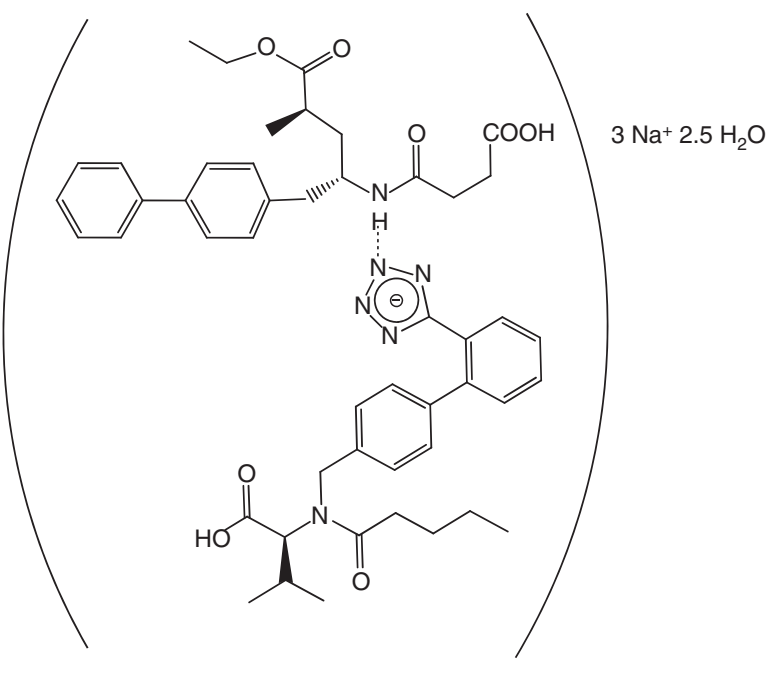

LCZ-696

Figure 4 Structures of next generation ARBs. Examples of chemical structures of some next generation ARBs.

more effectively than did a 30 -fold greater dose of valsartan. ${ }^{43}$ Although the mechanisms that mediate the potent renoprotective effects of K-868 remain to be determined, its ability to limit kidney damage might be in part due to its ability to inhibit inflammatory cytokine production through the partial activation of $\operatorname{PPAR} \gamma$. As $\operatorname{PPAR} \gamma$ activation can also reduce C-reactive protein levels, another inflammatory mediator of risk for target organ damage and diabetes, it will also be of interest to determine whether K-868 has any special capacity to reduce $\mathrm{C}$-reactive protein levels compared with other ARBs that do not affect PPAR $\gamma$-related pathways. Given the potential metabolic and renoprotective benefits of K-868, this molecule holds promise not only for preventing new onset diabetes in hypertensive patients more effectively than existing ARBs, but also for improving glucose metabolism and limiting kidney damage in patients with diabetes and hypertension.

In addition to K-868 that is under development by Kyowa Hakko Kirin, another compound with bivalent pharmacology of $\mathrm{AT}_{1}$ receptor antagonism and partial PPAR $\gamma$ agonism has been studied by Pfizer (New York, NY, USA). Pfizer has identified an $\mathrm{AT}_{1}$ antagonist PF03838135 that has been available for out-licensing and that has blood pressure-lowering effects in spontaneously hypertensive rats comparable with those of telmisartan but with greater potency than telmisartan on PPAR $\gamma$ activation. ${ }^{44}$ In the Zucker diabetic fatty rat model, PF-03838135 has been reported to show insulin-sensitizing effects that are greater than those of telmisartan and comparable with those of the full PPAR $\gamma$ agonist pioglitazone while inducing less weight gain than pioglitazone. Taken together, the observations with telmisartan, K-868 and PF-03838135 support the feasibility of identifying next generation $\mathrm{ARBs}$ with the potent ability to antagonize $\mathrm{AT}_{1}$ receptors and simultaneously activate $\operatorname{PPAR} \gamma$ with the goal of providing greater metabolic benefits than those afforded by first generation $\mathrm{AT}_{1}$ receptor antagonists with little or no effect on PPAR $\gamma$ activity.

\section{NEXT GENERATION ARBS THAT INHIBIT NEPRILYSIN ACTIVITY}

Neprilysin (also called neutral endopeptidase or NEP) is a membranebound zinc metallopeptidase that metabolizes a number of small secreted vasoactive peptides involved in blood pressure homeostasis, including the natriuretic peptides and bradykinin. Additional bioactive peptide substrates for neprilysin include Leu- and Met-enkephalin, vasointestinal polypeptide and amyloid- $\beta$ peptide. For a review on neprilysin and its function, see Turner et al. ${ }^{45}$

As the natriuretic peptides have vasodilatory, natriuretic and diuretic properties, it was hypothesized and shown experimentally that the pharmacological inhibition of neprilysin to potentiate natriuretic peptide activity results in blood pressure-lowering effects. A number of companies pursued the discovery and development of neprilysin inhibitors for the treatment of hypertension and heart failure, and modest antihypertensive activities of such molecules were shown in a number of clinical trials. However, the full potential of neprilysin inhibition was only realized in combination with concomitant inhibition of the angiotensin-converting enzyme (ACE), which culminated in the discovery and development of the vasopeptidase inhibitors, compounds that combined both neprilysin and ACE inhibitory activity in a single small molecule. ${ }^{46}$

The clinically most advanced vasopeptidase inhibitor was omapatrilat, which was discovered and developed by Bristol-Myers Squibb (New York, NY, USA). Clinical hypertension trials have shown broadly 
superior antihypertensive efficacy of omapatrilat relative to enalapril, ${ }^{47}$ and good efficacy was also shown in heart failure. ${ }^{48,49}$ However, the 3 -fold higher incidence of angioedema observed for omapatrilat relative to enalapril, and the incidence of life-threatening angioedema in the late-stage clinical studies led to the discontinuation of omapatrilat in 2002 because of the unfavorable risk-benefit profile. ${ }^{50}$ As both ACE and neprilysin are key enzymes in the metabolism of bradykinin, it is hypothesized that dual inhibition of ACE and neprilysin by omapatrilat and other vasopeptidase inhibitors results in a significantly greater elevation of bradykinin levels relative to ACE inhibition alone, which in a subset of patients can lead to excessive vascular leakage, fluid extravasation and angioedema, explaining the unfavorable tolerability issues observed for omapatrilat. ${ }^{51}$

The objective of two current drug research and development programs conducted by Theravance (South San Francisco, CA, USA) and Novartis is the discovery of compounds that replicate the superior efficacy of omapatrilat through dual inhibition of the RAS and neprilysin, but without elevation of bradykinin levels and associated high risk for angioedema. This is achieved through inhibition of the RAS at the level of the $\mathrm{AT}_{1}$ receptor rather than at the level of the converting enzyme, which is the rate-limiting enzyme in bradykinin metabolism. The concept was first shown experimentally in two separate studies in the spontaneously hypertensive rat model of hypertension..$^{52,53}$ For example, in the study of $\mathrm{Pu}$ et al., ${ }^{52}$ it was shown that treatment with the ARB valsartan and a neprilysin inhibitor in combination resulted in equivalent blood pressure-lowering and comparable effects on vascular remodeling and cardiac fibrosis compared to treatment with a vasopeptidase inhibitor. The group of Hegde et al. ${ }^{54}$ at Theravance has recently described a rat model for tracheal plasma extravasation. Omapatrilat and lisinopril produced robust and dose-dependent increases in plasma extravasation in the anesthetized rat, which is consistent with their demonstrated clinical risk for angioedema. Increased plasma extravasation by those two compounds in this model appears to be mediated by bradykinin, as pre-treatment with the bradykinin receptor antagonist HOE-140 completely blocked the response. In contrast to the effect of low doses of omapatrilat, even high doses of the angiotensin receptor blocker valsartan, a neprilysin inhibitor or their combination failed to produce a measurable increase in tracheal plasma extravasation. Taken together, these data suggest that dual inhibition of the $\mathrm{AT}_{1}$ receptor and neprilysin has the potential to produce similar antihypertensive effects as omapatrilat, but without the risk of angioedema. ${ }^{54}$

Theravance is pursuing the discovery of novel dual-acting antihypertensive agents that have $\mathrm{AT}_{1}$ receptor antagonist and neprilysin inhibitory activity in the same molecule ( $\mathrm{AT}_{1}$ Receptor Blocker and Neprilysin Inhibitor, (ARNIs)). The initial results of Theravance's ARNI program have appeared recently in a series of published patent applications. ${ }^{55-58}$ Theravance describes a structurally diverse series of compounds that generally contain an aryl acid moiety and a zincchelating group such as a hydroxamate or thiol. These bifunctional compounds are reported to bind to the $\mathrm{AT}_{1}$ receptor and also inhibit neprilysin activity.

Although the compounds discovered by Theravance combine the $\mathrm{AT}_{1}$ blocking and neprilysin inhibitor activities in single small bifunctional molecules, Novartis describes their drug candidate LCZ-696 as a 1:1 molar complex of the ARB valsartan with the neprilysin inhibitor prodrug AHU-377 (Figure 4). The patent literature characterizes the complex as a multicomponent salt between valsartan, the neprilysin inhibitor, one or more cations and solvent molecules. ${ }^{59-61}$ Although this complex is not a bifunctional single molecule, it is described as a distinct crystal form that has different properties from the simple physical mixture of the two active compounds. However, as a fixed-dose combination of two drugs, the complex would not result in matched DMPK properties and might still lead to temporal dissociation in pharmacodynamic activity at the two targets and with this to suboptimal efficacy. Novartis recently reported encouraging data from a phase II study, showing superior blood pressure reduction of the combination relative to valsartan alone in patients with mild to moderate hypertension, without any reported cases of angioedema, which clinically validates the concept of dual inhibition of the $\mathrm{AT}_{1}$ angiotensin receptor and neprilysin. ${ }^{62}$ At the high dose of $400 \mathrm{mg}$, LCZ-696-treated patients showed a $20 \mathrm{~mm} \mathrm{Hg}$ reduction in SBP relative to baseline. This compares very favorably with the $14 \mathrm{~mm} \mathrm{Hg}$ reduction seen for $320 \mathrm{mg}$ valsartan in the study, considering that the effective dose of valsartan in the $400 \mathrm{mg}$ dose of the LCZ696 combination is about $200 \mathrm{mg}$, assuming a 1:1 molar complex between the ARB and the neprilysin inhibitor. LCZ-696 is also being studied for the treatment of heart failure.

\section{NEXT GENERATION ARBS THAT BLOCK ENDOTHELIN RECEPTORS}

Endothelin-1 is a very potent vasoconstricting peptide and its dysregulation can contribute to the development of high blood pressure. The actions of endothelin-1 are mediated by two G-protein coupled receptors, the $\mathrm{ET}_{\mathrm{A}}$ and $\mathrm{ET}_{\mathrm{B}}$ endothelin receptors, which are expressed in smooth muscle and in the endothelial cells of the vasculature. ${ }^{63}$ Three endothelin receptor antagonists are approved and clinically used for the treatment of pulmonary arterial hypertension: bosentan, sitaxentan and ambrisentan. ${ }^{64}$ Recent clinical data for another endothelin antagonist, darusentan, which is developed by Gilead Sciences (Foster City, CA, USA), also establishes the use of this class of compounds for the treatment of hypertension. ${ }^{65}$

A number of preclinical studies have established that dual blockade of $\mathrm{AT}_{1}$ and endothelin receptors results in greater blood pressurelowering effects than does the blockade of either receptor alone. ${ }^{6-69}$ An early series of dual $\mathrm{AT}_{1}$ and ET receptor antagonists was described by Merck, ${ }^{70}$ following the recognition of structural and functional similarities between the endothelin and $\mathrm{AT}_{1}$ receptors, and similar structure-activity relationships seen for their peptide agonist ligands. A starting point for the discovery of bifunctional $\mathrm{AT}_{1} / \mathrm{ET}_{\mathrm{A}}$ antagonists was the existing Merck library of compounds blocking the $\mathrm{AT}_{1}$ receptor. Subsequent structure-activity relationship studies resulted in the identification of L-746,072, which showed potent binding affinity toward all four receptor subtypes $\left(\mathrm{IC}_{50} \mathrm{~s}\right.$ for $\mathrm{AT}_{1}=13 \mathrm{nM}$, $\left.\mathrm{AT}_{2}=32 \mathrm{nM}, \mathrm{ET}_{\mathrm{A}}=24 \mathrm{nM}, \mathrm{ET}_{\mathrm{B}}=60 \mathrm{nM}\right)$. However, no preclinical or clinical data have been reported for this compound.

A program at Bristol-Myers Squibb pursued the converse approach, starting with lead discovery efforts with potent and selective $\mathrm{ET}_{\mathrm{A}}$ receptor antagonists. It was realized that the common core structure (a biphenyl sulfonamide) in endothelin antagonist leads was bioisosteric with the biphenyl carboxylates and biphenyl tetrazoles found in most of the marketed sartan ARBs. ${ }^{71}$ A dedicated medicinal chemistry program focused on increasing the $\mathrm{AT}_{1}$ activity of the endothelin receptor antagonist scaffold, while maintaining and further enhancing activity at the $\mathrm{ET}_{\mathrm{A}}$ receptor. This effort led to the discovery of a number of dual action receptor antagonist compounds, which were shown to be potent and selective for inhibition of the $\mathrm{AT}_{1}$ and $\mathrm{ET}_{\mathrm{A}}$ receptors, with only low affinities for the $\mathrm{AT}_{2}$ and $\mathrm{ET}_{\mathrm{B}}$ receptors. BMS248360 , a first generation dual action receptor antagonist lead compound, showed high affinity for the $\mathrm{ET}_{\mathrm{A}}$ receptor, with somewhat lower affinity at the $\mathrm{AT}_{1}$ receptor $\left(\mathrm{ET}_{\mathrm{A}} K_{\mathrm{i}}=1.9 \mathrm{nM}, \mathrm{AT}_{1} K_{\mathrm{i}}=10 \mathrm{nM}\right)$. The compound was orally bioavailable in rats with a good half life, 
and produced potent inhibition of angiotensin II and big ET-1 pressor responses in rats, showing its bifunctional in vivo activity for inhibition of both targets. ${ }^{72}$

Following the work on BMS-248360, further optimization studies led to the discovery of the second generation dual action receptor antagonist compound PS-433540 (BMS-346567) (Figure 4) with improved affinity at the $\mathrm{AT}_{1}$ receptor $\left(\mathrm{ET}_{\mathrm{A}} \mathrm{K}_{\mathrm{i}}=9.3 \mathrm{nM}, \mathrm{AT}_{1}\right.$ $\mathrm{K}_{\mathrm{i}}=0.8 \mathrm{nM}$ ), better pharmacodynamic activity at the two targets after oral dosing, and superior pharmacokinetic properties in higher species (dog and monkey). ${ }^{73}$ PS-433540 was shown to be more efficacious than irbesartan in the spontaneously hypertensive rat, which is considered a model for renin-dependent hypertension. ${ }^{71}$ PS-433540 was also effective in the DOCA-salt rat, ${ }^{74}$ which is a model of lowrenin hypertension in which $\mathrm{AT}_{1}$ receptor antagonists show relatively little or no efficacy. ${ }^{75}$

Bristol-Myers Squibb licensed PS-433540 to Pharmacopeia in 2006, and phase I clinical studies were initiated in early 2007. Ligand Pharmaceuticals (San Diego, CA, USA), which acquired Pharmacopeia in late 2008, recently reported results from a phase IIb study, in which three doses of PS-433540 (200, 400 and $800 \mathrm{mg}$ ) were directly compared with $300 \mathrm{mg}$ of the ARB irbesartan or placebo after 12 weeks of treatment. ${ }^{76}$ PS- 433540 at all doses resulted in a significant lowering of mean-seated SBP and DBP relative to baseline, with higher doses resulting in more blood pressure lowering. The efficacy of the $800 \mathrm{mg}$ dose was significantly different from that of the $300 \mathrm{mg}$ dose of irbesartan, with SBP/DBP reductions of $23 / 14 \mathrm{~mm} \mathrm{Hg}$ for PS-433540, and $11 / 7 \mathrm{~mm} \mathrm{Hg}$ for irbesartan, respectively. Importantly, the blood pressure goal of less than $140 / 90 \mathrm{~mm} \mathrm{Hg}$ was reached by 62 and $52 \%$ of patients treated with the 800 and $400 \mathrm{mg}$ doses of PS- 433540 , whereas only $32 \%$ of patients reached this goal when treated with irbesartan. PS-433540 was generally well tolerated; however, about $11 \%$ of patients experienced peripheral edema at the $800 \mathrm{mg}$ dose, relative to $2 \%$ of patients treated with placebo and $3 \%$ of patients treated with irbesartan. Although the data presented for this compound to date suggest superior efficacy relative to ARBs alone, the relative contribution of endothelin receptor blockade toward overall efficacy is unclear at present.

\section{NEXT GENERATION ARBS THAT ARE NO DONORS}

Nitric oxide (NO) is a potent gaseous signaling molecule with complex chemistry and biology. It is generated by a number of cell types in response to various stimuli, and because of its very short half life and spatially limited range of activity is considered a local autocrine and paracrine signaling molecule with both beneficial and deleterious downstream effects, depending on its localization and effective concentration. ${ }^{77} \mathrm{NO}$ is produced by the endothelial cells of the blood vessels, and was identified in 1986 as the elusive endothelium-derived relaxing factor. ${ }^{78,79}$ Its actions are mainly mediated by activation of the enzyme soluble guanylate cyclase, which catalyzes the production of cyclic guanosine monophosphate (cGMP) from GTP, resulting in the activation of a number of cGMP-dependent protein kinases that mediate the downstream effects. In humans, NO has been shown to have a major role in modulating vascular tone. It also has pronounced antithrombotic activity, as well as protective effects in the heart and the kidneys. ${ }^{80}$ Dysregulation of the NO system is associated with cardiovascular disease, and reduced NO bioactivity is considered to be an important determinant of endothelial dysfunction and hypertension. ${ }^{81}$

A number of academic groups and biopharmaceutical companies are pursuing the discovery and development of $\mathrm{NO}$ donor hybrid drugs, which are molecules that contain a NO-donor moiety linked to an existing drug with well-established pharmacological properties. ${ }^{82}$ The additional NO-releasing activity of such bifunctional compounds can either improve the efficacy of the compounds and/or counteract the adverse effects. An example for the latter is naproxcinod, which is the hybrid of an NO donor with the nonsteroidal anti-inflammatory drug naproxen. The compound should carry the anti-inflammatory properties of naproxen, but without its adverse effects on blood pressure and the gastrointestinal system. ${ }^{83}$

A group from the University of Pisa in Italy has described the synthesis and characterization of NO-donor analogs of losartan and its active metabolite EXP-3174..$^{84,85}$ The bifunctional nature of the compounds was assessed using in vitro organ bath preparations of rat endothelium-denuded aortic rings. ARB-NO hybrids mediated concentration-dependent relaxation of aortic rings pre-contracted with $\mathrm{KCl}$, which was blocked in the presence of ODQ, an inhibitor of guanylate cyclase, showing the activation of the NO-cGMP pathway by the compound. $\mathrm{AT}_{1}$ antagonist activity of compounds was confirmed in a similar assay by assessing the inhibition of contractile responses to angiotensin II. The lead compound, the 3-[(nitrooxy)methyl] benzoate ester of losartan (Figure 4), also showed a significant lowering of SBP in spontaneously hypertensive rats after 4 weeks of oral or subcutaneous dosing, with equivalent effects to losartan at equimolar doses. Importantly, this compound was shown to be cardioprotective in a model of myocardial ischemia and reperfusion, whereas losartan essentially showed no activity. Also, it inhibited platelet aggregation to a greater extent than losartan. Both activities can be attributed to the additional NO-releasing group of the bifunctional compound, differentiating it pharmacologically from the monofunctional ARB.

A group from the China Pharmaceutical University in Nanjing, China, has explored NO-releasing derivatives of telmisartan using an approach similar to that of Breschi et al ${ }^{84-86}$ The lead compound WB1106 was found to have dual activity in isolated rat aortic preparations and significantly reduced angiotensin II-mediated pressor responses in normotensive rats. WB1106 lowered blood pressure in spontaneously hypertensive rats to the same extent as telmisartan, but, in contrast to telmisartan, increased aortic cGMP levels, with similar magnitude as the ACE inhibitor, fosinopril. In high-fat and carbohydrate-fed rats, WB1106 effectively reduced body weight gain and fasting serum glucose levels and significantly improved oral glucose tolerance, all more effectively than did equimolar doses of telmisartan, possibly reflecting the synergistic effects of $\mathrm{NO}$ and telmisartan on glucose metabolism. Several ARBs containing one or more NO-donor groups have also been described in a series of published patent applications by Merck (Whitehouse Station, NJ, USA) and NiCox (Sophia Antipolis, France). ${ }^{87-89}$

\section{CONCLUSIONS AND PERSPECTIVE}

Although the renin-angiotensin system has an important role in the pathogenesis of hypertension and related cardiovascular and metabolic disorders, it is clear that the use of ARBs to inhibit RAS activity is not sufficient to control blood pressure and the risk for cardiovascular disease and diabetes in many patients. On the basis of advances in medicinal chemistry, it has become possible to design new classes of ARBs that are multifunctional and show pharmacological activities in addition to $\mathrm{AT}_{1}$ receptor antagonism. Such molecules can target multiple pathophysiological pathways in cardiovascular disease and diabetes besides just the upregulation of the renin-angiotensin system. Although the discovery of such multifunctional compounds is more complex and the optimal ratio of potencies for the different 
targets needs to be found, the unified pharmacokinetics should allow for better-matched pharmacodynamic activities at the two targets, compared with simple combination therapy. Furthermore, a multifunctional molecule is also amenable to a fixed-dose combination with other drugs, which allows for three or more pharmacologies in a single pill. An important consideration in the design of multifunctional ARBs is the kind of activity added to the molecule, as maximal efficacy benefits will be achieved when adding a target mechanism that is complementary to, or synergistic with, RAS blockade. By going beyond inhibition of the RAS, the next generation ARBs described herein could be of considerable clinical value and provide greater therapeutic benefits than molecules that work only through the $\mathrm{AT}_{1}$ receptor blockade.

\section{CONFLICT OF INTEREST}

TWK is the recipient of grants from the National Institutes of Health and has received lecture honoraria from GlaxoSmithKline, Boehringer-Ingelheim, Pfizer, and Merck, consultant fees from Theravance Inc., Kyowa Hakko Kirin Pharmaceuticals, and Takeda Pharmaceuticals North America, and holds stock ownership interest in GlaxoSmithKline, Bristol Myers Squibb, Bethesda Pharmaceuticals, Ligand Pharmaceuticals, Novartis, and Pfizer. UK is an employee of Theravance Inc.

1 Duncia JV, Chiu AT, Carini DJ, Gregory GB, Johnson AL, Price WA, Wells GJ, Wong PC Calabrese JC, Timmermans PB. The discovery of potent nonpeptide angiotensin II receptor antagonists: a new class of potent antihypertensives. J Med Chem 1990; 33: 1312-1329.

2 Ram CV. Angiotensin receptor blockers: current status and future prospects. Am J Med 2008; 121: 656-663.

3 McMurray JJ. ACE inhibitors in cardiovascular disease-unbeatable? N Engl J Med 2008; 358: 1615-1616.

4 Matchar DB, McCrory DC, Orlando LA, Patel MR, Patel UD, Patwardhan MB, Powers B, Samsa GP, Gray RN. Systematic review: comparative effectiveness of angiotensinconverting enzyme inhibitors and angiotensin II receptor blockers for treating essential hypertension. Ann Intern Med 2008; 148: 16-29.

5 Gavras I, Gavras H. Are patients who develop angioedema with ACE inhibition at risk of the same problem with AT1 receptor blockers? Arch Intern Med 2003; 163: 240-241.

6 Haymore BR, Yoon J, Mikita CP, Klote MM, DeZee KJ. Risk of angioedema with angiotensin receptor blockers in patients with prior angioedema associated with angiotensin-converting enzyme inhibitors: a meta-analysis. Ann Allergy Asthma Immunol 2008; 101: 495-499.

7 Yusuf S, Teo KK, Pogue J, Dyal L, Copland I, Schumacher H, Dagenais G, Sleight P, Anderson $\mathrm{C}$. Telmisartan, ramipril, or both in patients at high risk for vascular events. $N$ Engl J Med 2008; 358: 1547-1559.

8 Maillard MP, Wurzner G, Nussberger J, Centeno C, Burnier M, Brunner HR. Comparative angiotensin II receptor blockade in healthy volunteers: the importance of dosing. Clin Pharmacol Ther 2002; 71: 68-76.

9 Oparil S, Silfani TN, Walker JF. Role of angiotensin receptor blockers as monotherapy in reaching blood pressure goals. Am J Hypertens 2005; 18(2 Part 1): 287-294.

10 Calhoun DA, Jones D, Textor S, Goff DC, Murphy TP, Toto RD, White A, Cushman WC, White W, Sica D, Ferdinand K, Giles TD, Falkner B, Carey RM. Resistant hypertension: diagnosis, evaluation, and treatment. A scientific statement from the American Heart Association Professional Education Committee of the Council for High Blood Pressure Research. Hypertension 2008; 51: 1403-1419.

11 Elliott WJ, Meyer PM. Incident diabetes in clinical trials of antihypertensive drugs: a network meta-analysis. Lancet 2007; 369: 201-207.

12 Gress TW, Nieto FJ, Shahar E, Wofford MR, Brancati FL. Hypertension and antihypertensive therapy as risk factors for type 2 diabetes mellitus. Atherosclerosis Risk in Communities Study. N Engl J Med 2000; 342: 905-912.

13 Kjeldsen SE, Naditch-Brule L, Perlini S, Zidek W, Farsang C. Increased prevalence of metabolic syndrome in uncontrolled hypertension across Europe: the Global Cardiometabolic Risk Profile in Patients with hypertension disease survey. J Hypertens 2008, 26: 2064-2070.

14 Redon J, Cifkova R, Laurent S, Nilsson P, Narkiewicz K, Erdine S, Mancia G. The metabolic syndrome in hypertension: European society of hypertension position statement. J Hypertens 2008; 26: 1891-1900.

15 Shargorodsky M, Hass E, Boaz M, Gavish D, Zimlichman R. High dose treatment with angiotensin II receptor blocker in patients with hypertension: differential effect of tissue protection versus blood pressure lowering. Atherosclerosis 2008; 197 303-310
16 Hollenberg NK, Parving HH, Viberti G, Remuzzi G, Ritter S, Zelenkofske S, Kandra A, Daley WL, Rocha R. Albuminuria response to very high-dose valsartan in type 2 diabetes mellitus. J Hypertens 2007; 25: 1921-1926.

17 Kaplan NM. Combination therapy for hypertension. Nat Rev Cardiol 2009; 6: 270-271.

18 Morphy R, Rankovic Z. Designed multiple ligands. An emerging drug discovery paradigm. J Med Chem 2005; 48: 6523-6543.

19 Neutel JM. Prescribing patterns in hypertension: the emerging role of fixed-dose combinations for attaining BP goals in hypertensive patients. Current Medical Research and Opinion 2008; 24: 2389-2401.

20 Benson SC, Pershadsingh HA, Ho Cl, Chittiboyina A, Desai P, Pravenec M, Qi N, Wang J, Avery MA, Kurtz TW. Identification of telmisartan as a unique angiotensin II receptor antagonist with selective PPAR \{gamma\}-modulating activity. Hypertension 2004; 43 993-1002.

21 Schupp M, Janke J, Clasen R, Unger T, Kintscher U. Angiotensin type 1 receptor blockers induce peroxisome proliferator-activated receptor-gamma activity. Circulation 2004; 109: 2054-2057.

22 Schupp M, Clemenz M, Gineste R, Witt H, Janke J, Helleboid S, Hennuyer N, Ruiz P, Unger T, Staels B, Kintscher U. Molecular characterization of new selective peroxisome proliferator-activated receptor \{gamma\} modulators with angiotensin receptor blocking activity. Diabetes 2005; 54: 3442-3452.

23 Yusuf S, Teo K, Anderson C, Pogue J, Dyal L, Copland I, Schumacher H, Dagenais G, Sleight $\mathrm{P}$. Effects of the angiotensin-receptor blocker telmisartan on cardiovascular events in high-risk patients intolerant to angiotensin-converting enzyme inhibitors: a randomised controlled trial. Lancet 2008; 372: 1174-1183.

24 Yusuf S, Diener HC, Sacco RL, Cotton D, Ounpuu S, Lawton WA, Palesch Y, Martin RH, Albers GW, Bath P, Bornstein N, Chan BP, Chen ST, Cunha L, Dahlof B, De Keyser J, Donnan GA, Estol C, Gorelick P, Gu V, Hermansson K, Hilbrich L, Kaste M, Lu C, Machnig T, Pais P, Roberts R, Skvortsova V, Teal P, Toni D, VanderMaelen C, Voigt T, Weber M, Yoon BW. Telmisartan to prevent recurrent stroke and cardiovascular events. N Engl J Med 2008; 359: 1225-1237.

25 Bosch J, Yusuf S, Gerstein HC, Pogue J, Sheridan P, Dagenais G, Diaz R, Avezum A, Lanas F, Probstfield J, Fodor G, Holman RR. Effect of ramipril on the incidence of diabetes. N Engl J Med 2006; 355: 1551-1562.

26 Dagenais GR, Pogue J, Fox K, Simoons ML, Yusuf S. Angiotensin-converting-enzyme inhibitors in stable vascular disease without left ventricular systolic dysfunction or heart failure: a combined analysis of three trials. Lancet 2006; 368: 581-588.

27 Lithell H, Hansson L, Skoog I, Elmfeldt D, Hofman A, Olofsson B, Trenkwalder P, Zanchetti A. The Study on Cognition and Prognosis in the Elderly (SCOPE): principal results of a randomized double-blind intervention trial. J Hypertens 2003; 21: 875-886.

28 Tomiyama H, Kushiro T, Abeta H, Ishii T, Takahashi A, Furukawa L, Asagami T, Hino T, Saito F, Otsuka Y. Kinins contribute to the improvement of insulin sensitivity during treatment with angiotensin converting enzyme inhibitor. Hypertension 1994; 23: 450-455.

29 Shiuchi T, Cui TX, Wu L, Nakagami H, Takeda-Matsubara Y, Iwai M, Horiuchi M. ACE inhibitor improves insulin resistance in diabetic mouse via bradykinin and NO. Hypertension 2002; 40: 329-334.

30 Bernobich E, de Angelis L, Lerin C, Bellini G. The role of the angiotensin system in cardiac glucose homeostasis: therapeutic implications. Drugs 2002; 62: 1295-1314.

31 Scheen AJ. Renin-angiotensin system inhibition prevents type 2 diabetes mellitus. Part 2. Overview of physiological and biochemical mechanisms. Diabetes Metab 2004; 30: 498-505.

32 Goebel M, Clemenz M, Staels B, Unger T, Kintscher U, Gust R. Characterization of new PPARgamma agonists: analysis of telmisartan's structural components. ChemMedChem 2009; 4: 445-456.

33 Jamerson KA, Nesbitt SD, Amerena JV, Grant E, Julius S. Angiotensin mediates forearm glucose uptake by hemodynamic rather than direct effects. Hypertension 1996; 27: 854-858.

34 Yusuf S, Ostergren JB, Gerstein HC, Pfeffer MA, Swedberg K, Granger CB, Olofsson B, Probstfield J, McMurray JV. Effects of candesartan on the development of a new diagnosis of diabetes mellitus in patients with heart failure. Circulation 2005; 112 : 48-53.

35 Takeda Global Research and Development Center. Efficacy and safety of TAK-536 in subjects with essential hypertension. ClinicalTrials.gov Identifier: NCT00759551. Available at: http://clinicaltrials.gov/ct2/show/NCT00759551?term=tak-536\&rank=1. Accessed June 22, 2009

36 Takeda Global Research and Development Center. An efficacy and safety study of TAK491 compared to valsartan and olmesartan in subjects with essential hypertension. ClinicalTrials.gov Identifier: NCT00696436. Available at: http://clinicaltrials.gov/ct2/ show/NCT00696436?term=azilsartan\&rank=8. Accessed June 22, 2009.

37 Takeda Pharmaceuticals Press Release. Takeda's investigational compound TAK-536 for treatment of hypertension enters into phase 3 Clinical Trials in Japan. Available at: http://www.takeda.com/press/article 34500.html. Accessed June 24, 2009.

38 Kohara Y, Kubo K, Imamiya E, Wada T, Inada Y, Naka T. Synthesis and angiotensin II receptor antagonistic activities of benzimidazole derivatives bearing acidic heterocycles as novel tetrazole bioisosteres. J Med Chem 1996; 39: 5228-5235.

39 Iwai M, Chen R, Imura Y, Horiuchi M. TAK-536, a new AT1 receptor blocker, improves glucose intolerance and adipocyte differentiation. Am J Hypertens 2007; 20: 579-586.

40 Takeda Global Research and Development Center. Efficacy and safety of TAK-491 combined with chlorthalidone in subjects with moderate to severe hypertension. 
ClinicalTrials.gov Identifier: NCT00847626. Available at: http://clinicaltrials.gov/ct2/ show/NCT00847626?term=tak-536\&rank=4. Accessed June 22, 2009.

41 ALLHAT Officers and Coordinators for the ALLHAT Collaborative Research Group. The Antihypertensive and Lipid-Lowering Treatment to Prevent Heart Attack Trial. Major outcomes in high-risk hypertensive patients randomized to angiotensin-converting enzyme inhibitor or calcium channel blocker vs diuretic: The Antihypertensive and Lipid-Lowering Treatment to Prevent Heart Attack Trial (ALLHAT). Jama 2002; 288: 2981-2997.

42 Black HR, Davis B, Barzilay J, Nwachuku C, Baimbridge C, Marginean H, Wright Jr JT, Basile J, Wong ND, Whelton P, Dart RA, Thadani U. Metabolic and clinical outcomes in nondiabetic individuals with the metabolic syndrome assigned to chlorthalidone, amlodipine, or lisinopril as initial treatment for hypertension: a report from the Antihypertensive and Lipid-Lowering Treatment to Prevent Heart Attack Trial (ALLHAT). Diabetes Care 2008; 31: 353-360.

43 Hamaguchi Y, Uchii M, Matsubara M, Yanagisawa A, Henmi K, Ueno K, Kusaka H, Yao K. A novel ARB with insulin-sensitizing activity, K-868, prevents diabetic nephropathy in rats. Diabetes 2009; 58(Suppl 1): A208-A209.

44 Pfizer Inc.. PF-03838135 non-confidential summary. 2008.

45 Turner AJ. Neprilysin. In: Barrett AJ, Rawlings D, Woessner JF (eds). Handbook of Proteolytic Enzymes. Elsevier: London, 2004, 419-426.

46 Weber MA. Vasopeptidase inhibitors. Lancet 2001; 358: 1525-1532.

47 Kostis JB, Packer M, Black HR, Schmieder R, Henry D, Levy E. Omapatrilat and enalapril in patients with hypertension: the Omapatrilat Cardiovascular Treatment vs. Enalapril (OCTAVE) Trial. Am J Hypertens 2004; 17: 103-111.

48 Packer M, Califf RM, Konstam MA, Krum H, McMurray JJ, Rouleau JL, Swedberg K. Comparison of omapatrilat and enalapril in patients with chronic heart failure: the Omapatrilat Versus Enalapril Randomized Trial of Utility in Reducing Events (OVERTURE). Circulation 2002; 106: 920-926.

49 Rouleau JL, Pfeffer MA, Stewart DJ, Isaac D, Sestier F, Kerut EK, Porter CB, Proulx G, Qian C, Block AJ. Comparison of vasopeptidase inhibitor, omapatrilat, and lisinopril on exercise tolerance and morbidity in patients with heart failure: IMPRESS randomised trial. Lancet 2000; 356: 615-620.

50 Zanchi A, Maillard M, Burnier M. Recent clinical trials with omapatrilat: new developments. Curr Hypertens Rep 2003; 5: 346-352.

51 Fryer RM, Segreti J, Banfor PN, Widomski DL, Backes BJ, Lin CW, Ballaron SJ, Cox BF, Trevillyan JM, Reinhart GA, von Geldern TW. Effect of bradykinin metabolism inhibitors on evoked hypotension in rats: rank efficacy of enzymes associated with bradykininmediated angioedema. Br J Pharmacol 2008; 153: 947-955.

52 Pu Q, Brassard P, Javeshghani DM, Iglarz M, Webb RL, Amiri F, Schiffrin EL. Effects of combined AT1 receptor antagonist/NEP inhibitor on vascular remodeling and cardiac fibrosis in SHRSP. J Hypertens 2008; 26: 322-333.

53 Gardiner SM, March JE, Kemp PA, Ballard SA, Bennett T. Regional hemodynamic effects of neutral endopeptidase inhibition and angiotensin (AT(1)) receptor antagonism alone or in combination in conscious spontaneously hypertensive rats. J Pharmacol Exp Ther 2006; 319: 340-348.

54 Hegde LG, Thibodeaux H, Yu C, Cheruvu M, Olsufka R, Renner T, Richardson C, Villarreal J, Armstrong SR, Hegde SS. Comparative preclinical assessment of angioedema risk of inhibitors of renin angiotensin system and neprilysin in the anesthetized rat tracheal plasma extravasation assay. FASEB J 2009; 23 (Abstracts): LB379.

55 Choi SK, Fatheree PR, Hedge S, Hudson R, Jendza K, Marquess D, McKinnell RM, Sasikumar V, Choi SK, Fatheree PR, Hedge S, Hudson R, Jendza K, Marquess D, McKinnell RM, Sasikumar V. Dual-acting antihypertensive agents. US patent application publication, US 2008/0188533.

56 Allegretti P, Choi SK, Gendron R, Fatheree PR, Jendza K, McKinnell RM, McMurtrie C, Olson B. Dual-acting imidazole antihypertensive agents. US patent application publication, US 2009/00232282009.

57 Allegretti P, Choi KS, Fatheree PR, Gendron R, Hudson R, Jendza K, McKinnell RM, McMurtrie C, Olson B. Dual-acting benzoimidazole antihypertensive agents. US patent application publication, US 2008/03189512008.

58 Allegretti PC, Gendron R, Fatheree PR, Jendza K, McKinnell RM, McMurtrie C, Olson B. Dual-acting antihypertensive agents. US patent application publication, US 2008/ 02693052008

59 Ksander GM, Webb RL. Methods of treatment and pharmaceutical composition. US patent 7,468,390.

60 Al-Fayoumi S, Hu J, Kumaraperumal N, Royce AE, Ruegger C, Zannou EA. Dual-acting pharmaceutical compositions based on superstructures of angiotensin receptor antagonist/blocker (ARB) and neutral endopeptidase (NEP) inhibitor. PCT International Application Publication 2009, WO 2009/0061713 A1.

61 Feng L, Godtfredsen SE, Karpinski P, Sutton PA, Prashad M, Girgis MJ, Hu B, Liu Y. Pharmaceutical combinations of an angiotensin receptor antagonist and an NEP inhibitor. PCT International Application Publication 2007, WO 2007/056546 A1.

62 Anonymous. Novartis highlights innovative approach to drug discovery with dynamic advance in exploratory pipeline. Pharmaceutical news and articles http://www.drugs. $\mathrm{com} /$ news/novartis-highlights-innovative-approach-discovery-dynamic-advanceexploratory-pipeline-14763. html. Accessed June 23, 2009.

63 Dhaun N, Goddard J, Kohan DE, Pollock DM, Schiffrin EL, Webb DJ. Role of endothelin-1 in clinical hypertension: 20 years on. Hypertension 2008; 52: 452-459.

64 Mucke HA. Pulmonary arterial hypertension: on the way to a manageable disease. Curr Opin Investig Drugs 2008; 9: 957-962.

65 Black HR, Bakris GL, Weber MA, Weiss R, Shahawy ME, Marple R, Tannoury G, Linas S, Wiens BL, Linseman JV, Roden R, Gerber MJ. Efficacy and safety of darusentan in patients with resistant hypertension: results from a randomized, double-blind, placebo-controlled dose-ranging study. J Clin Hypertens (Greenwich) 2007; 9: 760-769.

66 Massart PE, Hodeige DG, Van Mechelen H, Charlier AA, Ketelslegers JM, Heyndrickx $\mathrm{GR}$, Donckier JE. Angiotensin II and endothelin-1 receptor antagonists have cumulative hypotensive effects in canine Page hypertension. J Hypertens 1998; 16: 835-841.

67 Bohlender J, Gerbaulet S, Kramer J, Gross M, Kirchengast M, Dietz R. Synergistic effects of $A T(1)$ and $E T(A)$ receptor blockade in a transgenic, angiotensin II-dependent, rat model. Hypertension 2000; 35: 992-997.

68 Gardiner SM, March JE, Kemp PA, Mullins JJ, Bennett T. Haemodynamic effects of losartan and the endothelin antagonist, SB 209670, in conscious, transgenic ((mRen2)27), hypertensive rats. Br J Pharmacol 1995; 116: 2237-2244.

69 Ikeda T, Ohta H, Okada M, Kawai N, Nakao R, Siegl PK, Kobayashi T, Miyauchi T, Nishikibe M. Antihypertensive effects of a mixed endothelin-A- and -B-receptor antagonist, J-104132, were augmented in the presence of an AT1 -receptor antagonist, MK-954. J Cardiovasc Pharmacol 2000; 36 (5 Suppl 1): S337-S341.

70 Walsh TF, Fitch KJ, Williams Jr DL, Murphy KL, Nolan NA, Pettibone DJ, Chang RSL, O'Malley SS, Clineschmidt BV, Veber DF, Greenlee WJ. Potent dual antagonists of endothelin and angiotensin II receptors derived from alpha-phenoxyphenylacetic acids (part III). Bioorganic Medicinal Chemistry Letters 1995; 5: 1155-1158.

71 Kowala MC, Murugesan N, Tellew J, Carlson K, Monshizadegan H, Ryan C, Gu Z, Kane B, Fadnis L, Baska RA, Beyer S, Arthur S, Dickinson K, Zhang D, Perrone M, Ferrer P, Giancarli M, Baumann J, Bird E, Panchal B, Yang Y, Trippodo N, Barrish J, Macor JE. Novel dual action AT1 and ETA receptor antagonists reduce blood pressure in experimental hypertension. J Pharmacol Exp Ther 2004; 309: 275-284.

72 Murugesan N, Tellew JE, Gu Z, Kunst BL, Fadnis L, Cornelius LA, Baska RA, Yang Y, Beyer SM, Monshizadegan H, Dickinson KE, Panchal B, Valentine MT, Chong S, Morrison RA, Carlson KE, Powell JR, Moreland S, Barrish JC, Kowala MC, Macor JE. Discovery of $\mathrm{N}$-isoxazolyl biphenylsulfonamides as potent dual angiotensin II and endothelin A receptor antagonists. J Med Chem 2002; 45: 3829-3835.

73 Murugesan N, Gu Z, Fadnis L, Tellew JE, Baska RA, Yang Y, Beyer SM, Monshizadegan $H$, Dickinson KE, Valentine MT, Humphreys WG, Lan SJ, Ewing WR, Carlson KE, Kowala MC, Zahler R, Macor JE. Dual angiotensin II and endothelin A receptor antagonists: synthesis of 2 '-substituted N-3-isoxazolyl biphenylsulfonamides with improved potency and pharmacokinetics. J Med Chem 2005; 48: 171-179.

74 Floyd DM, Sills MA. Pre-clinical development of PS433540, a dual-acting receptor antagonist (DARA) of the angiotensin and endothelin receptors. J Clin Hypertens 2007; 9 (5, Suppl A): A158.

75 Pollock DM, Derebail VK, Yamamoto T, Pollock JS. Combined effects of AT(1) and ET(A) receptor antagonists, candesartan, and A-127722 in DOCA-salt hypertensive rats. Gen Pharmacol 2000; 34: 337-342.

76 Neutel JM, Graff A, Samson MB, Belder R, Zhang J, Kapil RP. PS433540, a dual angiotensin (AT1) and endothelin (ETA) receptor antagonist (DARA) demonstrates dosedependent blood pressure lowering effects better than irbesartan in phase IIb dose ranging study in stage 1 and stage II hypertensive patients. Presented at the 24th annual meeting of the American Society of Hypertension 2009; http://investors. ligand.com/releasedetail.cfm?ReleaselD=362687. Accessed June 22, 2009.

77 Stuart-Smith K. Demystified. Nitric oxide. Mol Pathol 2002; 55: 360-366.

78 Palmer RM, Ferrige AG, Moncada S. Nitric oxide release accounts for the biological activity of endothelium-derived relaxing factor. Nature 1987; 327: 524-526.

79 Ignarro LJ, Buga GM, Wood KS, Byrns RE, Chaudhuri G. Endothelium-derived relaxing factor produced and released from artery and vein is nitric oxide. Proc Natl Acad Sci USA 1987; 84: 9265-9269.

80 Loscalzo J, Welch G. Nitric oxide and its role in the cardiovascular system. Prog Cardiovasc Dis 1995; 38: 87-104

81 Giles TD. Aspects of nitric oxide in health and disease: a focus on hypertension and cardiovascular disease. J Clin Hypertens (Greenwich) 2006; 8(12 Suppl 4): 2-16.

82 Martelli A, Breschi MC, Calderone V. Pharmacodynamic hybrids coupling established cardiovascular mechanisms of action with additional nitric oxide releasing properties. Curr Pharm Des 2009; 15: 614-636.

83 Karlsson J, Pivodic A, Aguirre D, Schnitzer TJ. Efficacy, safety, and tolerability of the cyclooxygenase-inhibiting nitric oxide donator naproxcinod in treating osteoarthritis of the hip or knee. J Rheumatol 2009; 36: 1290-1297.

84 Breschi MC, Calderone V, Digiacomo M, Macchia M, Martelli A, Martinotti E, Minutolo F, Rapposelli S, Rossello A, Testai L, Balsamo A. New NO-releasing pharmacodynamic hybrids of losartan and its active metabolite: design, synthesis, and biopharmacological properties. J Med Chem 2006; 49: 2628-2639.

85 Breschi MC, Calderone V, Digiacomo M, Martelli A, Martinotti E, Minutolo F, Rapposelli S, Balsamo A. NO-sartans: a new class of pharmacodynamic hybrids as cardiovascular drugs. J Med Chem 2004; 47: 5597-5600.

86 Li YQ, Ji H, Zhang YH, Shi WB, Meng ZK, Chen XY, Du GT, Tian J. WB1106, a novel nitric oxide-releasing derivative of telmisartan, inhibits hypertension and improves glucose metabolism in rats. Eur J Pharmacol 2007; 577: 100-108.

87 Ali A, Lo MM-C, Franklin C, Almirante N, Stefanini S, Storoni L, Biondi S, Ongini E. Bis(nitrooxy) derivs. as angiotensin II receptor antagonists useful in the treatment of hypertension and their preparation. PCT International Application Publication 2009, WO 2009/070241 A2

88 Sebhat IK, Lo MM-C, Narugund RP, Ali A, Franklin C, Almirante N, Storoni L, Stefanini $\mathrm{S}$. Preparation of biphenyl compounds containing tetrazole moiety as angiotensin II receptor antagonists. PCT International Application Publication 2008, WO 2008/ 076246 A2.

89 Sebhat IK, Lo MM-C, Narugund RP, Ali A, Franklin C, Almirante N, Storoni L, Stefanini $\mathrm{S}$. Preparation of losartan dinitrate derivatives and related compounds as angiotensin II receptor antagonists. PCT International Application Publication WO 2008/076247 A2. 